\title{
Differential regulation of aldosterone synthase and $11 \beta$-hydroxylase transcription by steroidogenic factor-1
}

\author{
M H Bassett, Y Zhang, C Clyne, P C White ${ }^{1}$ and W E Rainey \\ Department of Obstetrics and Gynecology, University of Texas Southwestern Medical Center, 5323 Harry Hines Boulevard, Dallas, Texas 75390-9032, \\ USA \\ ${ }^{1}$ Department of Pediatrics, University of Texas Southwestern Medical Center, 5323 Harry Hines Boulevard, Dallas, Texas 75390-9032, USA \\ (Requests for offprints should be addressed to W E Rainey; Email: braine@mednet.swmed.edu)
}

\begin{abstract}
11 $\beta$-Hydroxylase (hCYP11B1) and aldosterone synthase (hCYP11B2) are closely related isozymes with distinct roles in cortisol and aldosterone production respectively. Aldosterone synthase catalyzes the final step in aldosterone biosynthesis and is expressed only in the zona glomerulosa of the normal adrenal. $11 \beta$-Hydroxylase catalyzes the final reaction in the production of cortisol and is expressed at higher levels in the zona fasciculata. The mechanisms causing differential expression of these genes are not well defined. Herein, we demonstrate contrasting roles for the orphan receptor steroidogenic factor-1 (SF-1) in the regulation of human $(h)$ CYP11B1 and hCYP11B2. Human NCl-H295R (H295R) or mouse Y-1 cells were transiently transfected with luciferase reporter constructs containing $5^{\prime}$-flanking regions of hCYP11B1, hCYP11B2, human 17 $\alpha$-hydroxylase (hCYP17), human cholesterol side-chain cleavage ( $h$ CYP11A1) or mouse $(m)$ cyp11b2 (mcyp11b2). Co-transfection of vectors encoding SF-1 increased expression of $h C Y P 11 B 1, h C Y P 11 A 1$ and $h C Y P 17$ constructs, but inhibited $h C Y P 11 B 2$ reporter activity. Murine, bovine and human SF-1 were unable to increase transcription of $h C Y P 11 B 2$ in H295R cells. Both hCYP11B2 and mcyp11b2 promoter constructs were inhibited similarly by human SF-1. In mouse Y-1 cells, reporter expression of $h C Y P 11 B 2$ and mcyp11b2 was very low compared with $h C Y P 11 B 1$ constructs, suggesting that this adrenal cell model may not be appropriate for studies of CYP11B2. Electrophoretic mobility shift assay demonstrated that SF-1 interacted with an element from both hCYP11B1 and hCYP11B2. However, mutation of this element, termed Ad4, did not prevent agonist stimulation of $h C Y P 11 B 2$ by angiotensin II or forskolin but blocked activity of $h C Y P 11 B 1$. In some, but not all, reports of genetic linkage analysis, a naturally occurring single nucleotide polymorphism within the Ad4 element of $h$ CYP11B2 $(-344 C / T)$ has been associated with cardiovascular disease. Herein, we have demonstrated that this polymorphism influenced binding of SF-1 in electrophoretic mobility shift assays, with the C allele binding SF-1 more strongly than the T allele. However, when hCYP11B2 constructs containing these alleles were transfected into H295R cells, there was no difference in agonist-stimulated expression or the response of either reporter construct to co-expression with human SF-1. Taken together, these data suggest that SF-1 and the Ad4 element are not major regulators of adrenal $h C Y P 11 B 2$ gene expression. Thus far, $h C Y P 11 B 2$ is the first steroid hydroxylase gene which is not positively regulated by SF-1.
\end{abstract}

Journal of Molecular Endocrinology (2002) 28, 125-135

\section{Introduction}

The adrenal cortex is the site of synthesis of the potent mineralocorticoid, aldosterone, and the glucocorticoid, cortisol. CYP11B2 (aldosterone synthase), which is expressed only within the zona glomerulosa of the adrenal cortex, is responsible for converting deoxycorticosterone to aldosterone (Kawamoto et al. 1990, Curnow et al. 1991, Domalik et al. 1991, Ogishima et al. 1992, LeHoux et al. 1995, Pascoe et al. 1995). On the other hand, CYP11B1 (11ß-hydroxylase) appears to be expressed predominantly in the fasciculata of the adrenal, where (in humans) it is responsible for the 
conversion of deoxycortisol to cortisol (Kawamoto et al. 1990, Curnow et al. 1991, Erdmann et al. 1995). In humans and rodents, the capacity of the adrenal cortex to differentially produce mineralocorticoid and glucocorticoid relies to a large extent on the zonal expression of the human (h) CYP11B isozymes which, in turn, ultimately depends upon the various cis-elements and trans-acting factors that control gene transcription.

The cis-elements controlling zone-specific expression lie mainly in the 5 -flanking regions of these genes. This has been demonstrated by genetic studies of individuals with glucocorticoidsuppressible hyperaldosteronism (GSH), an inherited form of hypertension in which CYP11B2 is expressed in a manner similar to the normal pattern of expression of CYP11B1. In GSH, $h C Y P 11 B 2$ is regulated by adrenocorticotropin $(\mathrm{ACTH})$ via cAMP-dependent signaling and it is expressed in the zona fasciculata. This disorder is caused by intergenic recombinations that juxtapose the $5^{\prime}$-flanking region and the first $2-4$ exons of CYP11B1 with coding sequences of CYP11B2 (Lifton et al. 1992a,b, Pascoe et al. 1992).

Several conserved cis-elements have been identified within the 5'-flanking region of CYP11B genes of different species (Rainey 1999). DNase I footprint analysis of the bovine (b) CRP11B 5'-flanking DNA demonstrated several regions, termed Adl through Ad6, that bound nuclear proteins (Morohashi et al. 1992a, Takayama et al. 1994). Similar sequences have been observed in the hCYP11B1 (Wang et al. 2000) and hCYP11B2 (Clyne et al. 1997) genes. Of these elements, Adl and Ad4 are required for cAMP-induced and basal transcription respectively of $h C Y P 11 B 1$ (Wang et al. 2000). The Ad4 sequence (AAGGCT/CG) is a nuclear receptor half-site which binds steroidogenic factor-1 (SF-1, also called Ad4 BP) (Ikeda et al. 1995, Morohashi \& Omura 1996), a monomeric orphan nuclear receptor that is required for the co-ordinated development and function of the adrenals and gonads. In the adult adrenal and gonad, SF-1 is essential for full expression of every steroid hydroxylase gene studied thus far, including cholesterol side-chain cleavage enzyme (GYP11A1) (Clemens et al. 1994, Liu \& Simpson 1997), 11ß-hydroxylase (CYP11B1) (Wang et al. 2000), 21-hydroxylase (CYP21) (Ikeda et al. 1993), 17 $\alpha$-hydroxylase/17,20 lyase (CYP17) (Givens et al. 1994, Bakke \& Lund 1995) and aromatase (CYP19)
(Michael et al. 1995). It is also required for full expression of other key components of steroidogenesis such as steroidogenic acute regulatory protein (Sugawara et al. 1997), 3ß-hydroxysteroid dehydrogenase type II (Leers-Sucheta et al. 1997) and the ACTH receptor (Cammas et al. 1997, Marchal et al. 1998).

However, the role of SF-1 in expression of hCYP11B2 is uncertain. Studies of a series of reporter constructs with serial deletions of the $5^{\prime}$-flanking region of $h C Y P 11 B 2$ suggested that the Ad4 element was not essential for expression (Clyne et al. 1997). On the other hand, a naturally occurring single nucleotide polymorphism involving this site $(-344 \mathrm{C} / \mathrm{T})$ has been implicated as affecting aldosterone levels, blood pressure, heart size and risk of myocardial infarction, although none of these associations has been consistently observed in all studies (White \& Slutsker 1995, Brand et al. 1998, Hautanen et al. 1998, Kupari et al. 1998, Davies et al. 1999, Hautanen et al. 1999, Schunkert et al. 1999, Tamaki et al. 1999, Patel et al. 2000, Ylitalo et al. 2000).

The current study was undertaken to clearly define the role of SF-1, the Ad4 element and the Ad4 polymorphism in hCYP11B2 expression. Our results have demonstrated that, while $\mathrm{SF}-1$ appears to play a critical role in $h C Y P 11 B 1$ transcription through interactions with the Ad4 element, this element and SF-1 do not play major roles in adrenal cell $h C Y P 11 B 2$ gene expression. Thus, hCYP11B2 is apparently the first of the human steroid hydroxylase genes which does not require SF-1 for full expression. The differences in the cis-elements that regulate $h C Y P 11 B 1$ and $h C Y P 11 B 2$ transcription may help to explain the differential expression of these isozymes within the adrenal cortex.

\section{Materials and methods}

\section{Preparation of reporter constructs and expression vectors}

A transient expression system using a luciferase reporter gene was used to characterize the Ad4/SF-1 binding site present in the hCYP11B1 (Wang et al. 2000), hCYP11B2 (Clyne et al. 1997) and mouse $(m)$ cyp11b2 (Bogerd et al. 1990) gene promoters. The hCYP11B1 (pB1-1102), hCYP11B2 (pB2-1521) and mcyp11b2 (pmB2-1500) constructs 
Table 1 Oligonucleotide sequences used as primers for site-specific mutagenesis or as probes for electrophoretic mobility shift assays (EMSA)

\section{Sequence}

$\begin{array}{llllllllllllll}\text { hCYP11B2 mAd4 } & 5^{\prime} & \text { AAG } & \text { AAT } & \text { CCg } & \text { Aat } & \text { tCC } & \text { CCT } & \text { CTC } & \text { ATC } & \text { TCA } & \text { CG } & & 3^{\prime} \\ \text { hCYP11B1 wtAd1 } & 5^{\prime} & \text { CCG } & \text { GTT } & \text { CTC } & \text { CCA } & \text { TGA } & \text { CGT } & \text { GAT } & \text { CCC } & \text { TCT } & \text { CGT } & \text { AC } & 3^{\prime} \\ \text { hCYP11B2 wtAd1 } & 5^{\prime} & \text { CCG } & \text { GTT } & \text { CTC } & \text { CCA } & \text { TGA } & \text { CGT } & \text { GAT } & \text { ATG } & \text { TTT } & \text { CGT } & \text { AC } & 3^{\prime} \\ \text { hCYP11B1 wtAd4 } & 5^{\prime} & \text { CCG } & \text { GTG } & \text { AAT } & \text { AAT } & \text { CCA } & \text { AGG } & \text { CTC } & \text { TTG } & \text { GAT } & \text { AGT } & \text { AC } & 3^{\prime} \\ \text { hCYP11B2 wtAd4 (C) } & 5^{\prime} & \text { CCG } & \text { GAA } & \text { AAG } & \text { AAT } & \text { CCA } & \text { AGG } & \text { CCC } & \text { CCT } & \text { CTC } & \text { AGT } & \text { AC } & 3^{\prime} \\ h C Y P 11 B 2 \text { wtAd4 (T) } & 5^{\prime} & \text { CCG } & \text { GAA } & \text { AAG } & \text { AAT } & \text { CCA } & \text { AGG } & \text { CTC } & \text { CCT } & \text { CTC } & \text { AGT } & \text { AC } & 3^{\prime}\end{array}$

The hCYP11B2 reporter construct with mutated (m) Ad4/SF-1 bases (lowercase letters) was produced using the indicated primer. EMSAs were performed using wild-type (wt)Ad1 and wtAd4 oligonucleotides corresponding to the indicated sequence in either hCYP11B1 or hCYP11B2. The hCYP11B2 Ad4 polymorphic oligonucleotides are indicated (C or T).

used in our study contained 1102, 1521 and 1500 bp 5'-flanking DNA respectively and were cloned into the promoterless pGL3-Basic luciferase reporter plasmid (Promega, Madison, WI, USA). Unless otherwise indicated, experiments involving the CYP11B2 plasmids refer to constructs containing the $\mathrm{C}$ allele at position -344 relative to the translation start site. For generation of the hCYP11B2 Ad4 mutant construct, the sequence 5'-CGAAGGCGC-3' ( - 344/ - 336) was changed to 5'-CcgAattCC-3' by site-specific mutagenesis (Stratagene, La Jolla, CA, USA) using the primer shown in Table 1 . The 5 '-flanking region of pSCG-4400 (Hu et al. 1999) was subcloned into the pGL3-Basic vector to generate the hCMP11A1 promoter plasmid, pA1-4400. The preparation of the hCIP17 promoter construct (pC17-1088) has been described previously (Hanley et al. 2001).

The coding sequences of mouse and bovine SF-1 were kindly provided by Keith Parker (University of Texas Southwestern Medical School, Dallas, TX, USA) and Ken-ichirou Morohashi (National Institute for Basic Biology, Okazaki, Japan) respectively. Human SF-1 was provided by Meera Ramayya (University of Washington, Seattle, WA, USA). Coding sequences for all three SF-1 plasmids were excised from their vectors and subcloned into the pRc/RSV expression plasmid (Invitrogen, Carlsbad, CA, USA). Keith Parker also supplied the mouse pmB2-1500 construct.

\section{Cell culture and transfection assay}

NCI-H295R (H295R) human adrenocortical tumor cells or mouse Y-1 adrenal tumor cells were cultured in Dulbecco's modified Eagle's/
Ham's F12 (DME/F12) medium (Gibco-BRL, Gaithersburg, MD, USA) supplemented with 2\% Ultroser G (BioSepra SA, Villeneuve la Garenne Cedex, France), 1\% ITS (Insulin Transferrin Selenium) Plus (Collaborative Research, Bedford, MA, USA) and antibiotics. We have previously described the use of the H295R and Y-1 cell lines to study the human CYP11B1 and CYP11B2 reporter constructs (Clyne et al. 1996, 1997, Wang et al. 2000). For transfection experiments, cells were subcultured onto 12-well culture dishes at a density of 300000 cells/well (H295R) or 150000 cells/well (Y-1) for use $36 \mathrm{~h}$ later. Transfection was carried out using 2.0 $\mu$ l Fugene (Roche, Indianapolis, IN, USA) and $1.0 \mu \mathrm{g}$ reporter plasmid DNA in DME/F12 medium $(1 \cdot 1 \mathrm{ml})$ for $6 \mathrm{~h}$ at $37^{\circ} \mathrm{C}$. For co-transfection experiments, various amounts of expression plasmids were included in the transfection reaction, and the total amount of DNA was kept constant by addition of carrier DNA (empty expression vector). Following transfection, cells were incubated with $2.0 \mathrm{ml}$ low serum medium (DME/F12 medium containing $0 \cdot 1 \%$ Ultroser G and antibiotics) for 18-24 h to allow for recovery and expression of foreign DNA. Where indicated, transfected cells were treated with agonists for $6 \mathrm{~h}$. Cells were then lysed and assayed for activity using the luciferase assay system (Promega).

\section{Electrophoretic mobility shift assay (EMSA)}

H295R nuclear extracts were prepared by the method of Schreiber et al. (1989). To prepare radiolabeled probe, double-stranded oligonucleotides $(25 \mathrm{pmol})$ containing $5^{\prime}$ protruding ends were labeled, by fill-in reaction, using $\left[\alpha_{-}^{-32} \mathrm{P}\right] \mathrm{dCTP}$ and 
Moloney murine leukemia virus reverse transcriptase at $37^{\circ} \mathrm{C}$ for $30 \mathrm{~min}$ (Gibco-BRL). Five micrograms of nuclear extract and each radiolabeled probe (40 000 d.p.m.) were incubated at room temperature for $20 \mathrm{~min}$ in $20 \mu \mathrm{l}$ reaction mixture (20 mM HEPES (pH 8.0), $80 \mathrm{mM} \mathrm{KGl,}$ $1 \mathrm{mM}$ EDTA, $10 \%$ glycerol, $1 \mathrm{mM}$ dithiothreitol, $0.5 \mathrm{mg} / \mathrm{ml}$ bovine serum albumin and $0.075 \mathrm{mg} /$ $\mathrm{ml}$ poly $\mathrm{dI}-\mathrm{dC}$ as non-specific competitor). For competition analysis, reaction mixtures containing various amounts of non-radiolabeled oligonucleotide were added simultaneously with probe. The resulting DNA/protein complexes were then separated from free probe by electrophoresis using a $4 \%$ high ionic strength native polyacrylamide gel with $1 \times$ Tris-glycine running buffer. The gel was dried and visualized following autoradiography at $-70{ }^{\circ} \mathrm{C}$ for $24 \mathrm{~h}$. Human SF-1 was prepared using a Promega in vitro transcription/translation system. The hCYP11B1- and hCYP11B2-specific Adl and Ad4 oligonucleotide sequences that were used for EMSA are listed in Table 1.

\section{Statistical analsysis}

Statistical comparison of means of three or more samples was accomplished by ANOVA. Significance was accepted at the 0.05 level of probability.

\section{Results}

\section{Comparison of the effects of SF-1 upon various steroidogenic enzymes}

Several steroidogenic P450 genes, including hCYP11B1 and hCYP11B2, contain consensus binding sites for SF-1 in their proximal 5'-flanking DNA. In order to examine the effects of SF-1 upon various steroidogenic enzymes, we co-transfected H295R cells with reporter constructs containing the 5'-flanking DNA of hCYP11A1 (pAl-4400), hCYP11B1 (pB1-1102), hCYP11B2 (pB2-1521) or hCYP17 (pC17-1088) with an expression plasmid containing the coding region of human SF-1. While hCYP11A1, hCYP11B1 and hCYP17 promoter activities increased significantly over basal levels (4-fold, 6-fold and 22-fold respectively), the activity of the hCYP11B2 promoter decreased by greater than 50\% when compared with basal levels of hCYP11B2 gene expression (Fig. 1). These

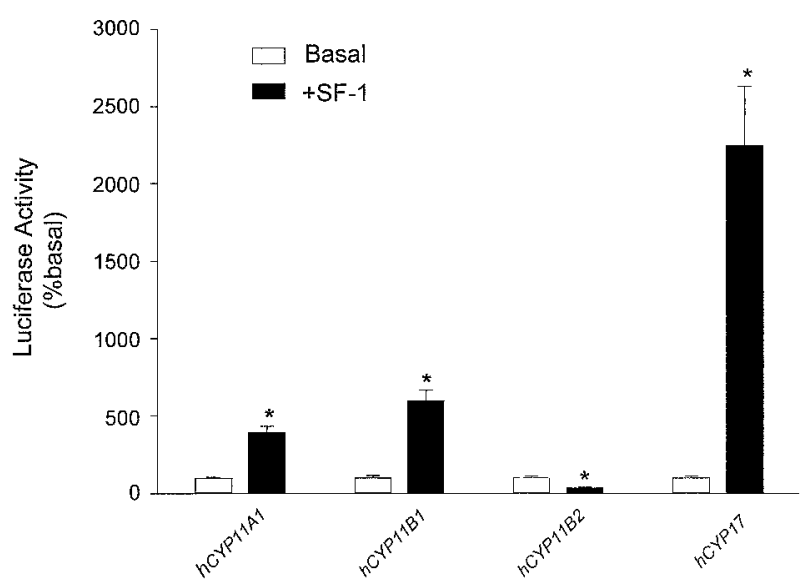

Figure 1 Comparison of the effects of SF-1 on transcription of various steroidogenic enzymes. H295R adrenocortical cells were transfected with luciferase reporter constructs containing 5'-flanking DNA (1 $\mathrm{\mu g} /$ well) from $h C Y P 11 A 1$ (pA1-4400), hCYP11B1 (pB1-1102), hCYP11B2 (pB2-1521) or hCYP17 (pC17-1088). Cells were co-transfected with either empty $\mathrm{pRc} / \mathrm{RSV}$ expression vector or the indicated amounts of human SF-1 expression plasmid $(1 \mu \mathrm{g} / \mathrm{ml})$ along with a $\beta$-galactosidase expression vector $(0.05 \mu \mathrm{g} /$ well). Twenty-four hours after transfection, cells were lysed and assayed for luciferase and $\beta$-galactosidase activity. Data were normalized to $\beta$-galactosidase and expressed as a percentage of the basal reporter activity of pA1-4400, pB1-1102, pB2-1521 or pC17-1088. Results represent the means \pm S.E.M. of data from at least three independent experiments each performed in triplicate. ${ }^{\star} P<0 \cdot 0001$.

data suggest that the regulation of hCYP11B2 transcription is quite different from that of the other cytochrome $\mathrm{P} 450$ genes involved in steroid metabolism. The following experiments were designed to determine if indeed hCYP11B2 represents the first steroidogenic cytochrome P450 gene that is not positively regulated by SF-1.

\section{Concentration-dependent effects of SF-1 on $h C Y P 11 B 1$ and $h C Y P 11 B 2$ reporter gene activity}

In order to clarify the role of $\mathrm{SF}-1$ in the transcriptional regulation of the two $h C Y P 11 B$ genes, we co-transfected H295R cells with pB1-1102 or pB2-1521 and increasing concentrations of an expression vector containing the coding sequence for human SF-1. As shown in Fig. 2, the hCYP11B1 promoter was activated by SF-1 in a concentration-dependent manner; 


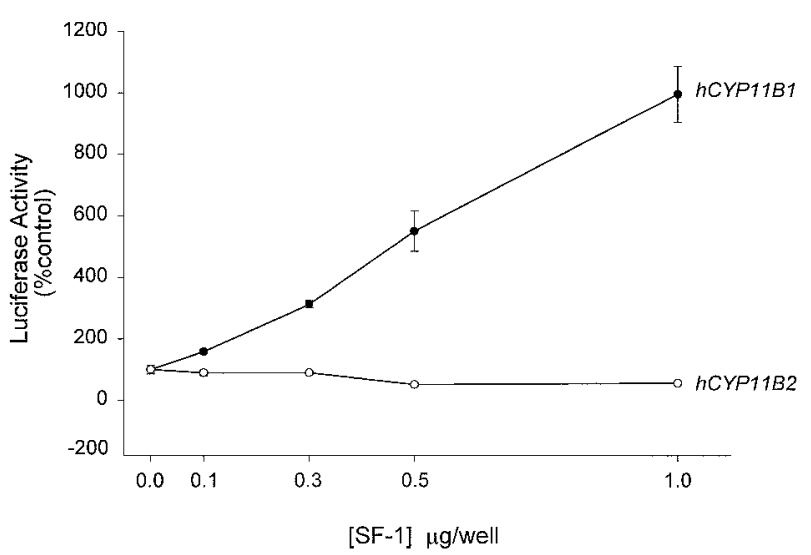

Figure 2 Concentration-dependent effects of SF-1 on $h C Y P 11 B 1$ and $h C Y P 11 B 2$ reporter gene activity. H295R adrenocortical cells were transfected with luciferase reporter constructs containing pB1-1102 or pB2-1521 5'-flanking DNA (1 $\mu \mathrm{g} /$ well). Cells were co-transfected with either empty pRc/RSV expression vector or the indicated amounts of human SF-1 expression plasmid along with a $\beta$-galactosidase expression vector $(0.05 \mu \mathrm{g} / \mathrm{well})$. Following recovery for $24 \mathrm{~h}$, cells were lysed and assayed for luciferase and $\beta$-galactosidase activity. Data were normalized to $\beta$-galactosidase and expressed as a percentage of the basal reporter activity of pB1-1102 or pB2-1521. Results represent the means \pm S.E.M. of data from two independent experiments each performed in triplicate.

activity increased to 10-fold above basal levels when cells were co-transfected with $1 \mu \mathrm{g}$ SF-1 plasmid. In contrast, we observed a reduction of luciferase activity by $44 \%$ for the $h C Y P 11 B 2$ reporter at $1 \mu \mathrm{g}$ SF-1 expression plasmid.

\section{The response of $h C Y P 11 B 1$ and $h C Y P 11 B 2$ to mouse, bovine and human SF-1}

There have been conflicting reports in the literature regarding the importance of the $\mathrm{Ad} 4$ element in the transcriptional regulation of the CrP11B2 gene (Bogerd et al. 1990, Clyne et al. 1997, LeHoux \& Lefebvre 1998). We therefore compared the ability of SF-1 from three different species to transactivate the human CYP11B1 or CYP11B2 gene promoters. As shown in Fig. 3, mouse, bovine and human SF-1 proteins were able to activate the $h C Y P 11 B 1$ promoter plasmid but failed to stimulate $h C Y P 11 B 2$.

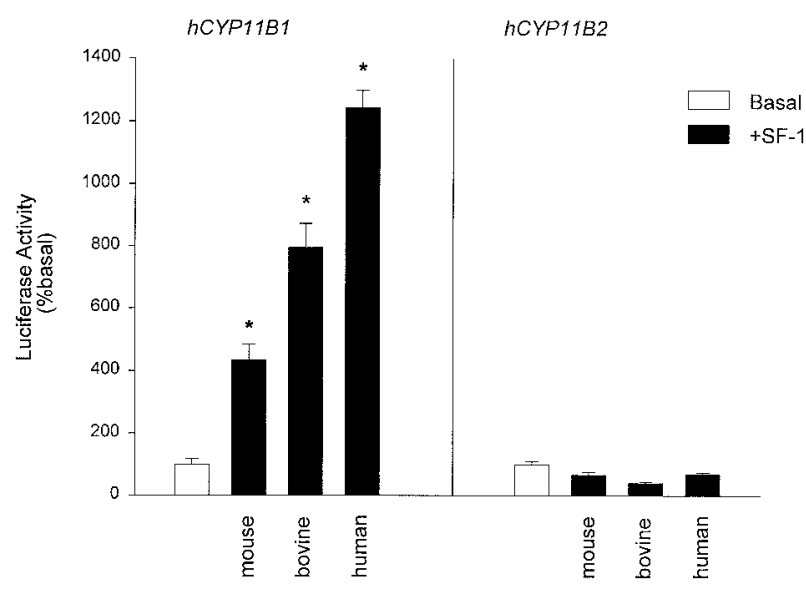

Figure 3 Comparison of the effects of mouse, human and bovine SF-1 on hCYP11B1 and hCYP11B2 transcription. H295R adrenocortical cells were transfected with luciferase reporter constructs containing pB1-1102 or pB2-1521 5'-flanking DNA ( $1 \mu \mathrm{g} / \mathrm{well})$. Cells were co-transfected with either empty pRc/RSV expression vector or the indicated SF-1 expression plasmid $(1 \mu \mathrm{g} / \mathrm{ml})$. Following recovery for $24 \mathrm{~h}$, cells were lysed and assayed for luciferase activity. Data are expressed as a percentage of the basal reporter activity of $\mathrm{pB} 1-1102$ or $\mathrm{pB} 2-1521$. The results in each panel represent the means \pm S.E.M. of data from three independent experiments, each one done in triplicate. ${ }^{*} P<0.0001$.

\section{Comparison of the effects of SF-1 on human CYP11B2 and mouse cyp11b2 reporter constructs}

Initial transfection studies of the mouse cyp11b2 promoter in mouse $\mathrm{Y}-1$ adrenal tumor cells suggested that the Ad4/SF-1 element was important for basal transcription (Bogerd et al. 1990). Therefore, we compared the ability of human SF-1 to stimulate human or mouse cyp11b2 reporter constructs in both human H295R and Y-1 adrenal cells (Fig. 4). SF-1 failed to stimulate reporter activity for either the mouse or human CYP11B2 promoter constructs in the human H295R cell line. SF-1 did slightly induce human (2-fold) and mouse $(1 \cdot 25$-fold) CYP11B2 reporter construct activity in mouse Y-1 cells. However, the basal activity of the hCYP11B2 reporter constructs in Y-1 cells is only $3 \%$ of the basal activity observed with the hCYP11B1 promoter vector, whereas in H295R cells the basal activity of the $h C Y P 11 B 2$ reporter is generally $1 \cdot 5$ - to 2-fold greater than that of hCYP11B1 (data not shown). 


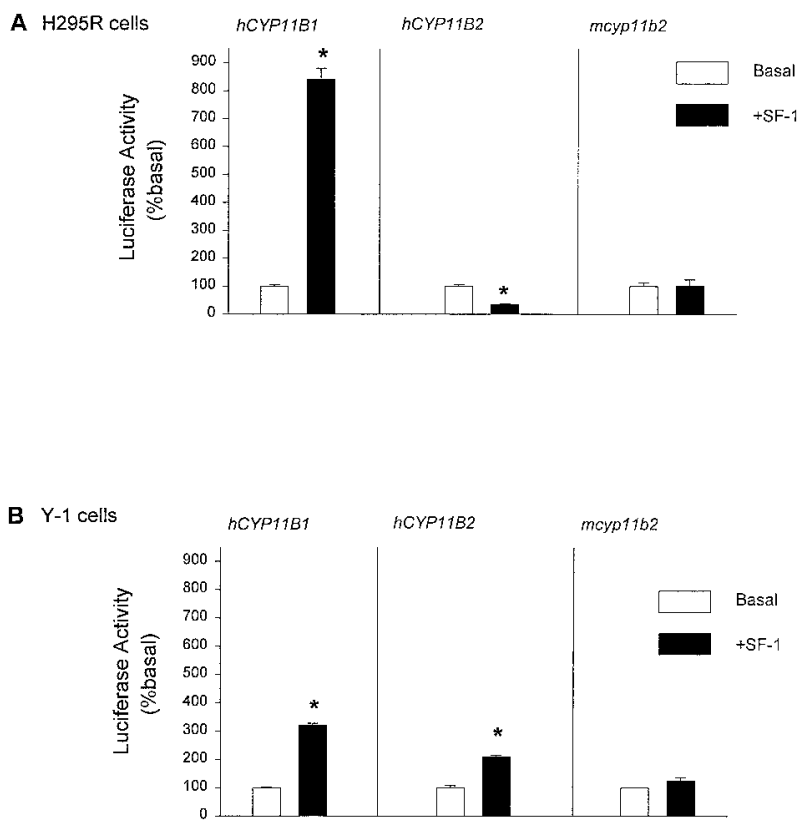

Figure 4 Comparison of the effects of SF-1 on mouse and human CYP11B2 reporter constructs in H295R and $\mathrm{Y}-1$ adrenal cells. (A) Transcriptional regulation of $h C Y P 11 B 2$ and mcyp11b2 by SF-1 in human H295R cells. (B) Transcriptional regulation of $h C Y P 11 B 2$ and mcyp 11 b2 by SF-1 in mouse Y-1 cells. H295R and Y-1 adrenocortical cells were transfected with luciferase reporter constructs containing pB1-1102, pB2-1521 or pmB2-1500 5'-flanking DNA (1 $\mu \mathrm{g} / \mathrm{well})$. Cells were co-transfected with either empty pRc/RSV expression vector or human SF-1 expression plasmid $(1 \mu \mathrm{g} / \mathrm{ml})$. Following recovery for $24 \mathrm{~h}$, cells were lysed and assayed for luciferase activity. Data are expressed as a percentage of the basal reporter activity of pB1-1102, pB2-1521 or pmB2-1500. The results in each panel represent the means \pm S.E.M. of data from three independent experiments, each one done in triplicate. ${ }^{*} P<0.0001$.

\section{The role of the Ad4 element in regulating hCYP11B1 and hCYP11B2 transcription}

There is good evidence suggesting an important role for the Ad4 element in bCYP11B and hCYP11B1 transcription (Morohashi et al. 1992b, Wang et al. 2000). In order to determine if differences in transcriptional regulation of the $h C Y P 11 B$ genes are due to binding properties of SF-1 to the hCYP11B1 and hCYP11B2 Ad4 consensus sequence, EMSA was carried out using both Ad4 sequences (Fig. 5). In the presence of H295R nuclear extract and the specific Ad4 oligonucleotides for $h C Y P 11 B 1$ or $h C Y P 11 B 2$, at least two major DNA/protein complexes were

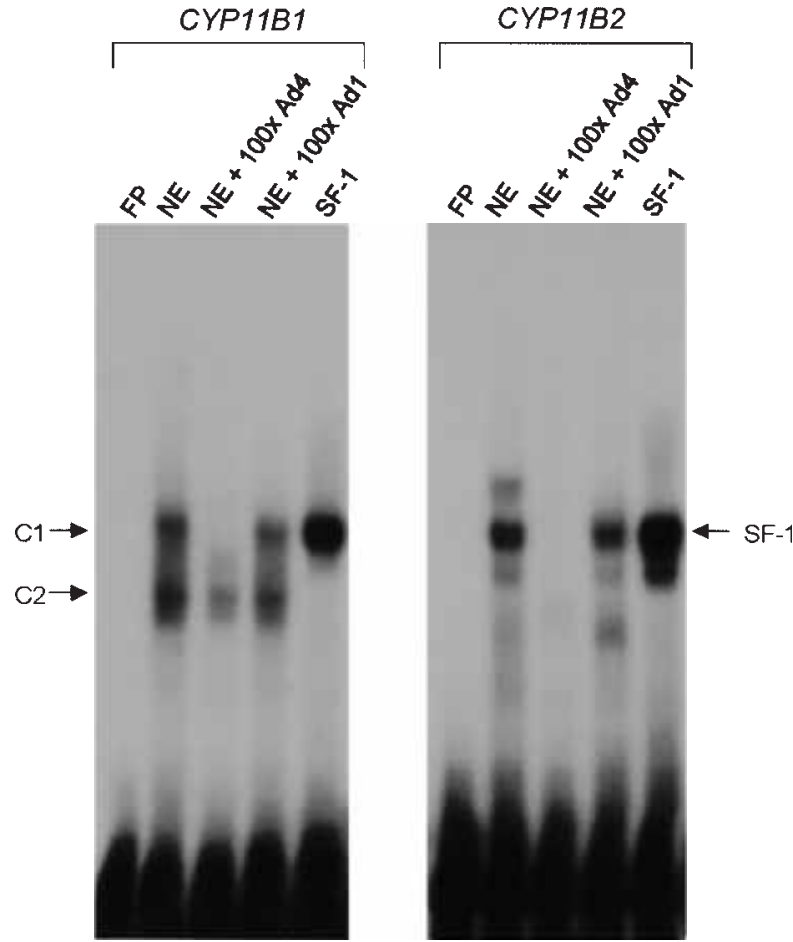

Figure 5 EMSA of the Ad4 consensus SF-1 binding sequence in $h C Y P 11 B 1$ and $h C Y P 11 B 2$. EMSA was performed using a ${ }^{32} \mathrm{P}$-labeled oligonucleotide probe corresponding to $h C Y P 11 B 1$ or hCYP11B2 Ad4 (Table 1). Samples containing radiolabeled probe alone (FP) or probe incubated with $5 \mu \mathrm{g} \mathrm{H} 295 \mathrm{R}$ nuclear extract (NE) are shown. Protein/DNA complexes (C1 and C2) were separated from free probe by gel electrophoresis. Non-radiolabeled self-competitor DNA $(\mathrm{NE}+100 \times \mathrm{Ad} 4)$ or non-specific Ad1 oligonucleotide $(\mathrm{NE}+100 \times \mathrm{Ad} 1)$ was added to the reaction mixture in a 100 -fold molar excess in order to identify non-specific protein/DNA interactions. Lanes labeled SF-1 show binding activity for $h C Y P 11 B 1$ and $h C Y P 11 B 2$ in the presence of in vitro prepared SF-1.

detected. One of the complexes (C1) was displaced from both labeled Ad4 sequences by the addition of a 100-fold molar excess of non-radiolabeled competitor but failed to be displaced by a non-specific oligonucleotide (Adl). These results indicated that the $\mathrm{Cl}$ complex represented a specific protein/DNA interaction. Additionally, in vitro translated SF-1 protein formed a complex with both of the Ad4 oligonucleotides; these SF-1/oligo complexes co-migrated with the $\mathrm{Cl}$ band present in both the hCYP11B1 Ad4 and hCYP11B2 Ad4 elements.

Recently, we reported that mutation of the Ad4 consensus sequence of $h C Y P 11 B 1$ reduced basal, 
5'-AAGGCTCCC-3'

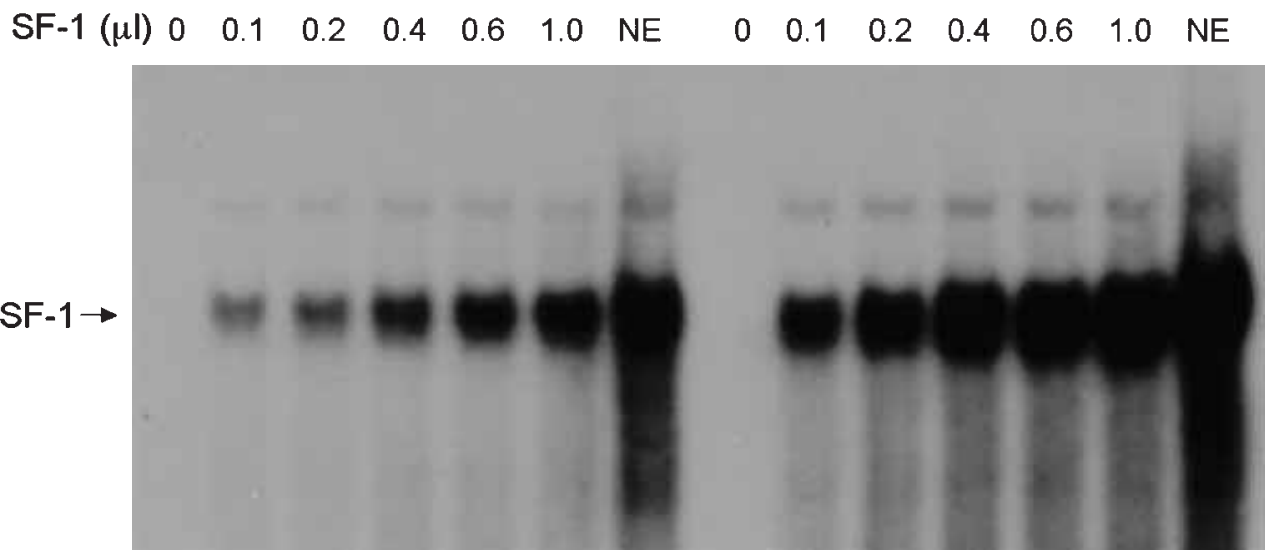

Figure 6 Effects on SF-1 binding of the $-344 \mathrm{C} / \mathrm{T}$ single nucleotide polymorphism in hCYP11B2. EMSA was performed using ${ }^{32} \mathrm{P}$-labeled oligonucleotide probes containing either the T allele (left panel) or C allele (right panel) of $h$ CYP11B2 (Table 1). Probes were incubated either in the absence of SF-1 (lanes 1 in each panel) or with increasing concentrations of in vitro synthesized SF-1 protein as indicated. The position of the band corresponding to SF-1 is indicated by an arrow to the left of the Figure. dibutyryl cyclic AMP-stimulated and SF-1transactivated reporter gene activity in H295R cells (Wang et al. 2000). In contrast, mutation of the Ad4 consensus sequence in the hCYP11B2 luciferase reporter plasmid had little effect on basal, angiotensin II (Ang II)- or forskolin-induced, or SF-1-stimulated activity when transfected into these cells (data not shown). Thus, the Ad4 element does not appear to be important for transcriptional regulation of $h C Y P 11 B 2$. These results confirmed and extended our previous observations using reporter constructs carrying serial deletions of the 5'-flanking region of hCYP11B2 (Clyne et al. 1997).

\section{Analysis of the single nucleotide polymorphism located within the Ad4 element of hCYP11B2}

Although these results demonstrated that the Ad4 element did not play a major role in regulating hCYP11B2 expression in H295R cells, previous reports had suggested that a single nucleotide polymorphism in the Ad4 element located 344 nucleotides $5^{\prime}$ to the translation initiation site of the gene might have important effects in vivo (White \& Slutsker 1995, Brand et al. 1998, Hautanen et al. 1998, 1999, Kupari et al. 1998, Davies et al. 1999, Schunkert et al. 1999, Tamaki et al. 1999, Patel et al. 2000, Ylitalo et al. 2000). This polymorphism
$(-344 \mathrm{C} / \mathrm{T})$ is located within the $\mathrm{AAGGC}(\mathrm{C} / \mathrm{T}) \mathrm{C}$ core sequence of the $\mathrm{Ad} 4 / \mathrm{SF}-1$ binding site. In order to assess the relative binding affinities of the $\mathrm{G}$ and T alleles, synthetic oligonucleotides containing these alleles were radiolabeled and used in EMSA (Fig. 6). When incubated in the presence of increasing concentrations of in vitro prepared human SF-1, both elements bound SF-1 in a concentration-dependent manner. However, the -344C allele bound SF-1 approximately five times more strongly than did the $-344 \mathrm{~T}$ allele. To determine if this single nucleotide difference affected gene expression, luciferase reporter constructs were prepared containing either the $\mathrm{C}$ or $\mathrm{T}$ allele. When these constructs were transfected into H295R cells, their expression was equally repressed by co-transfection with increasing concentrations of the SF-1 expression plasmid (Fig. 7A). Moreover, no allelic differences were observed for reporter construct activity under basal or forskolin treatments (Fig. 7B). However, a small preferential increase $(10 \%)$ in activity was observed for the $-344 \mathrm{C}$ allele after treatment with Ang II.

\section{Discussion}

SF-1 plays a pivotal role in the development of the adrenals and gonads. In addition, the expression of 
A
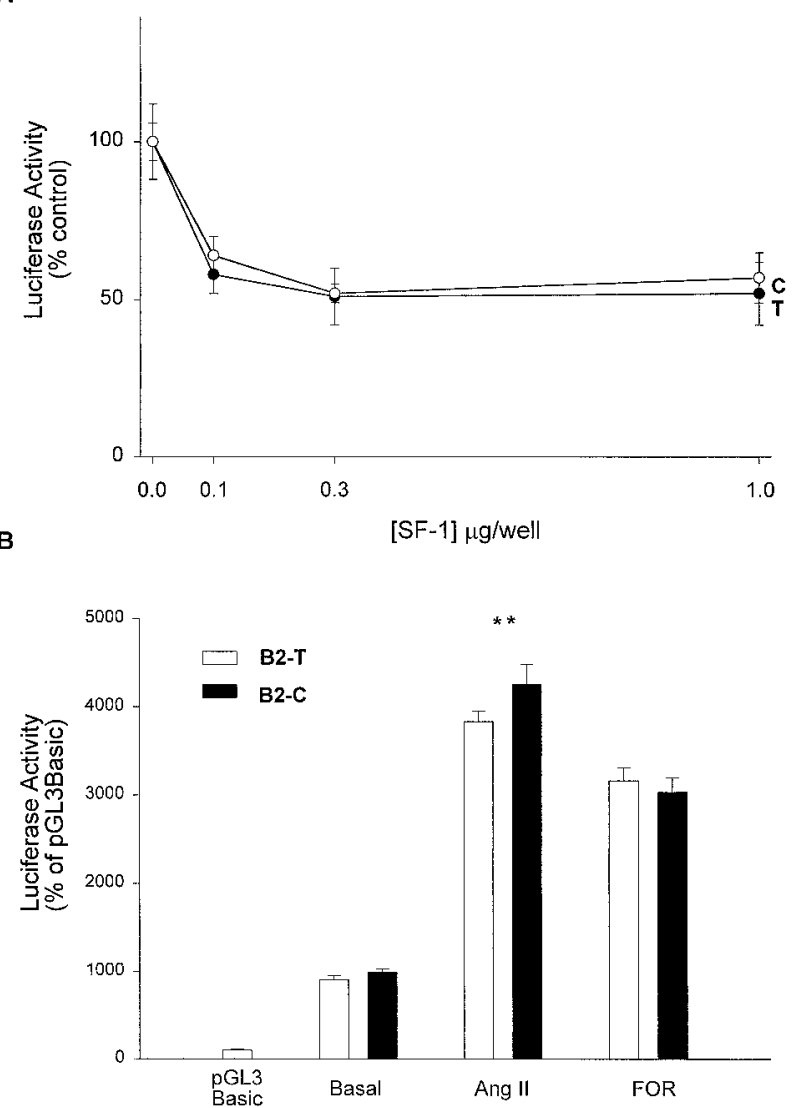

Figure 7 Effects on transcriptional activity of the $-344 \mathrm{C} / \mathrm{T}$ single nucleotide polymorphism of $h C Y P 11 B 2$. (A) SF-1 dose-response analysis of the T/C gene polymorphism using the $\mathrm{pB} 2-347 \mathrm{~T}$ (B2-T) and pB2347C (B2-C) promoter constructs. H295R adrenocortical cells were transfected with reporter constructs and either empty $\mathrm{pRc} / \mathrm{RSV}$ expression vector and/or the indicated amounts of SF-1 expression plasmid along with a $\beta$-galactosidase expression vector $(0.05 \mu \mathrm{g} / \mathrm{well})$. Following recovery for $24 \mathrm{~h}$, cells were lysed and assayed for luciferase and $\beta$-galactosidase activity. Data were normalized to $\beta$-galactosidase and expressed as a percentage of the basal reporter activity of pB2-347T or pB2-347C. Results represent the means \pm S.E.M. of data from four independent experiments each performed in triplicate. (B) Response of the T or C allele to treatment with agonist. Luciferase activities of lysates from control H295R cells or cells treated with Ang II $(10 \mathrm{nM})$ or forskolin (FOR; $10 \mu \mathrm{M}$ ) were measured. Results are expressed as a percentage of the activity of the pGL3-Basic construct and represent the means \pm S.E.M. of determinations from five independent experiments, each performed in triplicate. ${ }^{* *} P=0.0079$.

several of the enzymes involved in steroid hormone biosynthesis relies heavily on SF-1 for maximal gene transcription. However, the exact role of
SF-1 in the transcription of each of the individual cytochrome $\mathrm{P} 450$ genes that encode the steroid-metabolizing enzymes is less understood. Herein, we have used promoter constructs prepared using the 5 '-flanking DNA from the human CYP11A1, CYP17, CYP11B1 and CYP11B2 genes. Our data suggest that co-expression of SF-1 is very effective at activating transcription of CYP11A1, CYP17 and CYP11B1. However SF-1 does not appear to play an important role in the transcription of hCYP11B2.

\section{Role of SF-1 in hCYP11B2 expression}

There is a relatively high degree of sequence similarity between the first 400 bases located in the 5 -flanking regions of $h C Y P 11 B 1$ and $h C Y P 11 B 2$. Both promoters have identifiable consensus ciselements that were first characterized in the bCYP11B gene (Morohashi et al. 1992a, Takayama et al. 1994, Rainey 1999). Within the Ad4 elements of $h C Y P 11 B 1$ and $h C Y P 11 B 2,10$ out of 11 nucleotide bases are identical. Since hCYP11B1 is strongly up-regulated by SF-1 through the Ad4 element, the failure of SF-1 to stimulate CYP11B2 transcription - instead of its inhibition of reporter expression - seems surprising. Because CYP11B2 is unique among genes for steroidogenic enzymes in its negative response to SF-1, it is important to exclude trivial explanations for these observations. There could be a non-specific effect of the carrier vector on the promoter constructs. This is unlikely because the amount of DNA was kept constant in all transfections by the addition of empty expression vector. The inhibition could be a collateral effect of the specific expression vector used in our studies. This is also unlikely because the inhibition was observed when SF-1 was cotransfected in expression vectors driven by either RSV (pRc/RSV) or GMV (pcDNA 3·1) promoter (data not shown). The inhibition could be a squelching phenomenon related to the concentrations of SF-1 plasmid used in the study. While this is possible, the highest concentration used for co-transfection $(1 \mu \mathrm{g} / \mathrm{ml})$ was highly effective at stimulating $h C Y P 11 B 1$ as well as hCYP17 and hCYP11A1 promoter constructs. Another possibility could be an effect related to the species of SF-1 used in the expression vector. We tested human, bovine and mouse SF-1 and saw similar effects in each case. It is also possible that these results might 
apply only to the human CYP11B2 gene, but we obtained similar results with both human and mouse reporter constructs. Finally, while the inhibitory effect of SF-1 on hCYP11B2 reporter activity is surprising, there is a recent study suggesting that SF-1 does have a repressor domain (Ou et al. 2001). Further studies will be needed to determine if the inhibitory effect of SF-1 coexpression represents a physiologic effect that might occur in vivo.

The different results observed in H295R and Y-1 cells deserve comment. There were dramatic differences between the basal levels of reporter activity of $h C Y P 11 B 1$ and $h C Y P 11 B 2$ in transfected Y-1 cells; the activity of the $h C Y P 11 B 2$ reporter was only $3 \%$ of the activity observed for $h C Y P 11 B 1$. In contrast, basal levels of hCYP11B2 expression exceeded those of $h C Y P 11 B 1$ in transfected H295R cells. These results suggest that the Y-1 cell line may have adopted a phenotype similar to fasciculata cells, which express only low levels of hCYP11B2. In contrast, we have previously shown that H295R cells produce aldosterone and also express hCYP11B2 mRNA, which can be induced by Ang II and $\mathrm{K}^{+}$treatment (Bird et al. 1993, Denner et al. 1996, Pezzi et al. 1997). In that regard, the H295R cells may be a more appropriate in vitro model system than mouse Y-1 cells for attempting to define the cis- and trans-acting factors that control the regulation of $h C Y P 11 B 1$ and $h C Y P 11 B 2$ gene expression. Presumably, the inhibition of hCYP11B2 by SF-1 in H295R cells, and the slight stimulation of the same construct by SF-1 in Y-1 cells, are due to the differences in the type and concentration of specific binding proteins (corepressors or co-activators) present or absent in each cell type. Alternatively, it is conceivable that transcription factors needed for SF-1 to activate hCYP11B2 transcription are not present in the H295R cells. This concern is lessened by the fact that the H295R cells increase expression of hCYP11B2 mRNA following treatment with Ang II and $\mathrm{K}^{+}$.

\section{Role of the $-344 \mathrm{C} / \mathrm{T}$ polymorphism}

Several reports have associated the $-344 \mathrm{C} / \mathrm{T}$ polymorphism with variations in aldosterone secretion, blood pressure and other cardiovascular parameters (White \& Slutsker 1995, Brand et al. 1998, Hautanen et al. 1998, 1999, Kupari et al.
1998, Davies et al. 1999, Schunkert et al. 1999, Tamaki et al. 1999, Patel et al. 2000, Ylitalo et al. 2000), and we found clear allelic differences in the binding of SF-1 to the polymorphic Ad4 element. Thus, we felt it was possible that this polymorphism could modify the response of this gene to SF-1 and explain the previously noted associations. However, plasmids containing the two alleles were expressed at similar levels under both basal and forskolinstimulated conditions, and these plasmids were equally repressed when co-transfected with SF-1 expression plasmid. The small allelic difference in stimulation by Ang II is of uncertain significance. It is possible that this polymorphism has additional effects in vivo that cannot be modeled by reporter constructs in H295R cells, either because these effects require additional, and as yet unidentified, cis-elements within hCYP11B2, or because H295R cells lack necessary transcriptional factors. Alternatively, the observed in vivo associations may reflect genetic linkage disequilibrium between the $-344 \mathrm{C} / \mathrm{T}$ polymorphism and other polymorphisms elsewhere in or near hCYP11B2. Indeed, the $-344 \mathrm{C} / \mathrm{T}$ polymorphism is in linkage disequilibrium with a gene conversion in intron 2 of the hCYP11B2 gene (White \& Slutsker 1995) and also with a missense mutation, R173K (Mulatero et al. 2000).

The genes that encode the $h C Y P 11 B$ isozymes have clearly evolved distinct mechanisms to control transcription as indicated by their differential expression within the adrenal cortex. However, few studies to date have directly compared the mechanisms regulating these promoters. Herein, we have demonstrated that these genes vary dramatically in their requirement for SF-1, a transcription factor that has been proposed to be necessary for expression of most, if not all, cytochrome P450s involved in steroidogenesis. It is tempting to hypothesize that the lack of expression of $h C Y P 11 B 2$ in the zona fasciculata is, in part, due to the lack of sensitivity to SF-1. The contrasting requirements for SF-1 provide new insight into the differential regulation of these two closely related genes.

\section{Acknowledgements}

This work was supported by awards from the National Institutes of Health (DK43140 to W E R; DK37867 and DK54408 to PG W). We thank 
Keith Parker, Ken-ichirou Morohashi and Meera Ramayya for providing mouse, bovine and human SF-1 respectively.

\section{References}

Bakke M \& Lund J 1995 Mutually exclusive interactions of two nuclear orphan receptors determine activity of a cyclic adenosine $3^{\prime}, 5^{\prime}$-monophosphate-responsive sequence in the bovine CYP17 gene. Molecular Endocrinology 9 327-339.

Bird IM, Hanley NA, Word RA, Mathis JM, McCarthy JL, Mason JI \& Rainey WE 1993 Human NCI-H295 adrenocortical carcinoma cells: a model for angiotensin-II-responsive aldosterone secretion. Endocrinology 133 1555-1561.

Bogerd AM, Franklin A, Rice DA, Schimmer BP \& Parker KL 1990 Identification and characterization of two upstream elements that regulate adrenocortical expression of steroid 11 beta-hydroxylase. Molecular Endocrinology 4 845-850.

Brand E, Chatelain N, Mulatero P, Fery I, Curnow K, Jeunemaitre X, Corvol P, Pascoe L \& Soubrier F 1998 Structural analysis and evaluation of the aldosterone synthase gene in hypertension. Hypertension 32 198-204

Cammas FM, Pullinger GD, Barker S \& Clark AJ 1997 The mouse adrenocorticotropin receptor gene: cloning and characterization of its promoter and evidence for a role for the the orphan nuclear receptor steroidogenic factor 1. Molecular Endocrinology 11 867-876.

Clemens JW, Lala DS, Parker KL \& Richards JS 1994 Steroidogenic factor-1 binding and transcriptional activity of the cholesterol side-chain cleavage promoter in rat granulosa cells. Endocrinology 134 1499-1508.

Clyne CD, White PC \& Rainey WE 1996 Calcium regulates human CYP11B2 transcription. Endocrine Research 22 485-492.

Clyne CD, Zhang Y, Slutsker L, Mathis MM, White PC \& Rainey WE 1997 Angiotensin II and potassium regulate human CYP11B2 transcription through common cis-elements. Molecular Endocrinology 11 638-649.

Curnow KM, Tusie-Luna MT, Pascoe L, Natarajan R, Gu JL, Nadler JL \& White PC 1991 The product of the CYP11B2 gene is required for aldosterone biosynthesis in the human adrenal cortex. Molecular Endocrinology 5 1513-1522.

Davies E, Holloway CD, Ingram MC, Inglis GC, Friel EC, Morrison C, Anderson NH, Fraser R \& Connell JM 1999 Aldosterone excretion rate and blood pressure in essential hypertension are related to polymorphic differences in the aldosterone synthase gene CYP11B2. Hypertension 33 703-707.

Denner K, Rainey WE, Pezzi V, Bird IM, Bernhardt R \& Mathis JM 1996 Differential regulation of $11 \beta$-hydroxylase and aldosterone synthase in human adrenocortical H295R cells. Molecular and Cellular Endocrinology 121 87-91.

Domalik LJ, Chaplin DD, Kirkman MS, Wu RC, Liu WW, Howard TA, Seldin MF \& Parker KL 1991 Different isozymes of mouse 11 beta-hydroxylase produce mineralocorticoids and glucocorticoids. Molecular Endocrinology 5 1853-1861.

Erdmann B, Gerst H, Bulow HE, Lenz D, Bahr V \& Bernhardt R 1995 Zone-specific localization of cytochrome P45011B1 in human adrenal tissue by PCR-derived riboprobes. Histochemistry and Cell Biology 104 301-307.

Givens CR, Zhang P, Bair SR \& Mellon SH 1994 Transcriptional regulation of rat cytochrome $\mathrm{P} 450 \mathrm{c} 17$ expression in mouse Leydig MA-10 and adrenal Y-1 cells: identification of a single protein that mediates both basal and cAMP-induced activities. DNA and Cell Biology 13 1087-1098.

Hanley NA, Rainey WE, Wilson DI, Ball SG \& Parker KL 2001 Expression profiles of SF-1, DAX1, and CYP17 in the human fetal adrenal gland: potential interactions in gene regulation. Molecular Endocrinology 15 57-68.

Hautanen A, Lankinen L, Kupari M, Janne OA, Adlercreutz H, Nikkila H \& White PC 1998 Associations between aldosterone synthase gene polymorphism and the adrenocortical function in males. Fournal of Internal Medicine 244 11-18.

Hautanen A, Toivanen P, Manttari M, Tenkanen L, Kupari M, Manninen V, Kayes KM, Rosenfeld S \& White PC 1999 Joint effects of an aldosterone synthase (CYP11B2) gene polymorphism and classic risk factors on risk of myocardial infarction. Circulation $1002213-2218$

Hu MC, Chou SJ, Huang YY, Hsu NC, Li H \& Chung BC 1999 Tissue-specific, hormonal, and developmental regulation of $S C C$-LacZ expression in transgenic mice leads to adrenocortical zone characterization. Endocrinology 140 5609-5618.

Ikeda Y, Lala DS, Luo X, Kim E, Moisan MP \& Parker KL 1993 Characterization of the mouse FTZ-F1 gene, which encodes a key regulator of steroid hydroxylase gene expression. Molecular Endocrinology 7 852-860.

Ikeda Y, Luo X, Abbud R, Nilson JH \& Parker KL 1995 The nuclear receptor steroidogenic factor 1 is essential for the formation of the ventromedial hypothalamic nucleus. Molecular Endocrinology 9 478-486.

Kawamoto T, Mitsuuchi Y, Toda K, Miyahara K, Yokoyama Y, Nakao K, Hosoda K, Yamamoto Y, Imura H \& Shizuta Y 1990 Cloning of cDNA and genomic cDNA for human cytochrome P-45011 beta. FEBS Letters 269 345-349.

Kupari M, Hautanen A, Lankinen L, Koskinen P, Virolainen J, Nikkila H \& White PC 1998 Associations between human aldosterone synthase (CYP11B2) gene polymorphisms and left ventricular size, mass, and function. Circulation 97 569-575.

Leers-Sucheta S, Morohashi K, Mason JI \& Melner MH 1997 Synergistic activation of the human type II $3 \beta$-hydroxysteroid dehydrogenase/delta 5 -delta 4 isomerase promoter by the transcription factor steroidogenic factor-1/adrenal 4-binding protein and phorbol ester. Fournal of Biological Chemistry 272 7960-7967.

LeHoux JG \& Lefebvre A 1998 Transcriptional activity of the hamster CYP11B2 promoter in NCI-H295 cells stimulated by angiotensin II, potassium, forskolin and bisindolylmaleimide. Fournal of Molecular Endocrinology 20 183-191.

LeHoux JG, Martel D, LeHoux J, Ducharme L, Lefebvre A \& Briere N 1995 P450 aldo in hamster adrenal cortex: immunofluorescent and immuno-gold electron microscopic studies. Endocrine Research 21 275-280.

Lifton RP, Dluhy RG, Powers M, Rich GM, Cook S, Ulick S \& Lalouel JM $1992 a$ A chimaeric 11 beta-hydroxylase/aldosterone synthase gene causes glucocorticoid-remediable aldosteronism and human hypertension. Nature 355 262-265.

Lifton RP, Dluhy RG, Powers M, Rich GM, Gutkin M, Fallo F, Gill JR, Feld L, Ganguly A \& Laidlaw JC $1992 b$ Hereditary hypertension caused by chimaeric gene duplications and ectopic expression of aldosterone synthase. Nature Genetics 2 66-74.

Liu Z \& Simpson ER 1997 Steroidogenic factor-1 (SF-1) and SP1 are required for regulation of bovine CYP1 1A gene expression in bovine luteal cells and adrenal Y1 cells. Molecular Endocrinology 11 127-137.

Marchal R, Naville D, Durand P, Begeot M \& Penhoat A 1998 A steroidogenic factor-1 binding element is essential for basal human ACTH receptor gene transcription. Biochemical and Biophysical Research Communications 274 28-32.

Michael MD, Kilgore MW, Morohashi K \& Simpson ER 1995 Ad4 BP/SF-1 regulates cyclic AMP-induced transcription from the proximal promoter (pii) of the human aromatase p450 (cyp19) gene in the ovary. Fournal of Biological Chemistry 270 13561-13566.

Morohashi K \& Omura T 1996 Ad4 BP/SF-1, a transcription factor essential for the transcription of steroidogenic cytochrome P450 
genes and for the establishment of the reproductive function. FASEB fournal 10 1569-1577 (Review).

Morohashi K, Honda S, Inomata Y, Handa H \& Omura T $1992 a$ A shared promoter element regulates the expression of three steroidogenic enzymes. Molecular Endocrinology 5 1552-1561.

Morohashi K, Honda S, Inomata Y, Handa H \& Omura T $1992 b$ A common trans-acting factor, Ad4-binding protein, to the promoters of steroidogenic P-450s. Fournal of Biological Chemistry 267 17913-17919.

Mulatero P, Schiavone D, Fallo F, Rabbia F, Pilon C, Chiandussi L, Pascoe L \& Veglio F 2000 CYP11B2 gene polymorphisms in idiopathic hyperaldosteronism. Hypertension 35 694-698.

Ogishima T, Suzuki H, Hata J, Mitani F \& Ishimura Y 1992 Zone-specific expression of aldosterone synthase cytochrome P-450 and cytochrome P-45011 beta in rat adrenal cortex: histochemical basis for the functional zonation. Endocrinology 130 2971-2977.

Ou Q, Mouillet JF, Yan X, Dorn C, Crawford PA \& Sadovsky Y 2001 The DEAD box protein DP103 is a regulator of steroidogenic factor-1. Molecular Endocrinology 15 69-79.

Pascoe L, Curnow KM, Slutsker L, Connell JM, Speiser PW, New MI \& White PC 1992 Glucocorticoid suppressible hyperaldosteronism results from hybrid genes created by unequal crossovers between CYP1 1B1 and CYP11B2. PNAS 89 8327-8331.

Pascoe L, Jeunemaitre X, Lebrethon MC, Curnow KM, Gomez-Sanchez CE, Gasc JM, Saez JM \& Corvol P 1995 Glucocorticoid-suppressible hyperaldosteronism and adrenal tumors occurring in a single French pedigree. Fournal of Clinical Investigation 96 2236-2246.

Patel S, Steeds R, Channer K \& Samani NJ 2000 Analysis of promoter region polymorphism in the aldosterone synthase gene (CYP11B2) as a risk factor for myocardial infarction. American Fournal of Hypertension 13 134-139.

Pezzi V, Clyne CD, Ando S, Mathis JM \& Rainey WE 1997

$\mathrm{Ca}^{2+}$-regulated expression of aldosterone synthase is mediated by calmodulin and calmodulin-dependent protein kinases. Endocrinology 138 835-838.
Rainey WE 1999 Adrenal zonation: clues from 11ß-hydroxylase and aldosterone synthase. Molecular and Cellular Endocrinology 151 $151-160$

Schreiber E, Matthias P, Muller MM \& Schaffner W 1989 Rapid detection of octamer binding proteins with 'mini-extracts', prepared from a small number of cells. Nucleic Acids Research 176419.

Schunkert H, Hengstenberg C, Holmer SR, Broeckel U, Luchner A, Muscholl MW, Kurzinger S, Doring A, Hense HW \& Riegger GA 1999 Lack of association between a polymorphism of the aldosterone synthase gene and left ventricular structure. Circulation $992255-2260$.

Sugawara T, Kiriakidou M, McAllister JM, Kallen CB \& Strauss JF 1997 Multiple steroidogenic factor-1 binding elements in the human steroidogenic acute regulatory protein gene 5 '-flanking region are required for maximal promoter activity and cyclic AMP responsiveness. Biochemistry 36 7249-7255.

Takayama K, Morohashi K, Honda S, Hara N \& Omura T 1994 Contribution of Ad4 BP, a steroidogenic cell-specific transcription factor, to regulation of the human CYP11A and bovine CYP11B genes through their distal promoters. Fournal of Biochemistry 116 193-203.

Tamaki S, Iwai N, Tsujita Y \& Kinoshita M 1999 Genetic polymorphism of CYP11B2 gene and hypertension in Japanese. Hypertension 33 266-270.

Wang XL, Bassett M, Zhang Y, Yin S, Clyne C, White PC \& Rainey WE 2000 Transcriptional regulation of human 113-hydroxylase (hCYP11B1). Endocrinology $1413587-3594$.

White PG \& Slutsker L 1995 Haplotype analysis of CYP11B2. Endocrine Research 21 437-442.

Ylitalo A, Airaksinen KE, Hautanen A, Kupari M, Carson M, Virolainen J, Savolainen M, Kauma H, Kesaniemi YA, White PC \& Huikuri HV 2000 Baroreflex sensitivity and variants of the renin angiotensin system genes. Foumal of the American College of Cardiology 35 194-200.

Received 15 October 2001

Accepted 8 January 2002 